\title{
Studi Perhitungan Rele Tanah (Gfr) Akibat Gangguan Simpatetik Trip Pada Penyulang Tegangan Menengah
}

\author{
Tito Ganjar Nugroho'; Samsurizal ${ }^{2}$ \\ 1,2 Teknik Elektro (Institut Teknologi PLN) \\ samsurizal@itpln.ac.id
}

\begin{abstract}
Disturbances are generally in the form of short circuits which produce large short-circuit currents, so a protection system is needed to be able to minimize the extent of the impact of the fault current. In medium voltage networks, protection is needed to secure the network from interference along the conduit. The problem that often occurs in medium voltage network systems is sympathetic trip disorder, namely the failure of the relay in the uninterrupted feeder to join the trip together with the interrupted feeder. This incident occurred in the Windu feeder when there was a short circuit interruption of the single phase of the ground feeder at the Kosambi Duri Substation. Based on these events will be discussed how the influence of the disturbance current flowing to the point of disturbance and passing through the feeder relay, for that reason there needs to be an analysis related to setting the working time of the ground relay on the feeder. From the calculation results when there is a disturbance in the compact feeder where the ground work time relay is worth 0.294 seconds (working) and for Windu feeder when the compact is disturbed it is 0.333 . This minus value means that the relay should not work. It is suspected that Windu's feeder sympathetic is caused by an increase in phase voltage and creates new interference.
\end{abstract}

Keywords: protection system, sympathetic trip, relay, feeder

\begin{abstract}
ABSTRAK
Gangguan umumnya berupa hubung singkat yang menghasilkan arus hubung singkat yang besar maka sistem proteksi diperlukan untuk dapat meminimalisir meluasnya dampak arus gangguan. Pada jaringan tegangan menengah diperlukan proteksi untuk mengamankan jaringan dari gangguan di sepanjang penghantar. Masalah yang sering terjadi pada sistem jaringan tegangan menengah adalah gangguan simpatetik trip, yaitu kegagalan rele pada penyulang yang tidak terganggu ikut trip bersamaan dengan penyulang yang mengalami gangguan. Kejadian ini terjadi di penyulang Windu sewaktu adanya gangguan hubung singkat satu fasa ketanah penyulang Ringkik di Gardu Induk Duri Kosambi. Berdasarkan kejadian tersebut akan dibahas bagaimana pengaruh arus gangguan yang mengalir ke titik gangguan dan melewati rele penyulang, untuk itu perlu adanya analisa terkait penyetelan waktu kerja rele tanah pada penyulang tersebut. Dari hasil perhitungan saat terjadi gangguan di penyulang Ringkik dimana waktu kerja rele tanahnya bernilai 0,294 detik (bekerja) dan untuk penyulang Windu saat Ringkik terganggu bernilai -0,337 detik. Nilai minus ini artinya bahwa rele tersebut seharusnya tidak bekerja. Diduga simpatetik penyulang Windu disebabkan karena kenaikan tegangan fasanya dan menimbulkan gangguan baru.
\end{abstract}

Kata kunci: sistem proteksi, simpatetik trip, rele, penyulang 


\section{PENDAHULUAN}

Sistem distribusi adalah suatu sistem yang menyalurkan listrik dari gardu induk menuju konsumen. Pada sistem kelistrikan perlu suatu sistem distribusi $20 \mathrm{kV}$ untuk dapat menjamin kehandalan dalam penyaluran tenaga listrik antara produsen dan konsumen. Gangguan pelayanan menjadi indikator untuk tahu kehandalan pada sistem distribusi 20 $\mathrm{kV}$. Kehandalan merupakan hal yang penting untuk tetap dijaga, karena dapat sangat merugikan banyak pihak apabila tidak memenuhi standar [1].

Sistem proteksi yang memadai sangat mutlak diperlukan dalam memenuhi kehandalan dalam penyaluran energi listrik. Fungsi sistem proteksi disini sangat penting diperlukan untuk mengidentifikasi sewaktu ada gangguan dan memisahkan jaringan yang terganggu dari bagian lain yang masih dalam keadaan normal serta dapat mengamankan bagian ini dari kerusakan yang menyebabkan kerugian lebih besar. Gangguan bisa saja terjadi meskipun sudah dilengkapi dengan alat proteksi. Salah satu gangguan yang sering terjadi pada penyulang tegangan menengah adalah ikut tripnya penyulang lain saat adanya gangguan satu fasa ke tanah pada penyulang yang masih dalam satu busbar, kejadian seperti ini disebut simpatetik trip. Dimana saat kejadian tersebut, arus kapasitif yang dikandung penyulang yang tidak terganggu (penyulang sehat) mengalir menuju titik gangguan dan melalui rele tanah penyulang sehat. Bila setelan rele tanah ini lebih kecil dari besar arus kapasitif yang mengalir, maka rele tanah ini akan bekerja dan mengirim sinyal ke pemutus tenaga untuk trip. Normalnya pemutus tenaga yang membuka harus yang paling dekat gangguan, tidak boleh pemutus tenaga di penyulang sehat yang bekerja, hal ini agar daerah padam dapat diminimalkan.

Pada artikel yang berjudul Kajian Penyetelan Rele Proteksi Sehubungan Dengan Terjadinya Simpatetik Trip Pada Penyulang Tegangan Menengah di Gardu Induk Cengkareng [1]. Penulis melakukan kajian penyetelan rele GFR terhadap gangguan simpatetik trip pada penyulang. Dari hasil perhitungan diperoleh waktu kerja rele GFR pada 2 penyulang yaitu penyulang Garuda 1 dan Pertamina 1 saat penyulang lain gangguan adalah masing-masing $-0,412$ detik dan $-0,415$ detik. Pada tulisan lain yang berjudul Analisa Proteksi Pada Penyulang Distribusi Terhadap Terjadinya Gangguan Sympathetic Trip Di Gardu Induk Jatake [2]. Dalam tulisan lain penulis membahas mengenai penyebab Simpatetik trip dan melakukan setting ulang pada rele GFR. Dari hasil perhitungan diperoleh waktu kerja rele GFR antara 0,35 detik bekerja dan -0,71 detik tidak bekerja.

Adapun tujuan dari penelitian ini adalah menganalisa bagaimana gangguan simpatetik trip, apakah arus kapasitif dapat mempengaruhi terjadinya simpatetik ini dan mengalisis perhitungan waktu kerja rele tanahnya.

\section{METODE/PERANCANGAN PENELITIAN}

Untuk dapat menyelesaikan penelitian ini, maka perancangan penelitian yang disusun menggunakan beberapa tahapan yang terdiri dari :

- Studi Literatur, yaitu mencari dan mempelajari buku-buku, jurnal ilmiah, Handbook, dan artikel - artikel yang berisikan tentang teori atau pembahasan yang terkait dengan penelitian.

- Pengumpulan data, dengan cara pengamatan dan survei secara langsung ke lapangan dan pengambilan data di PT.PLN (Persero) Gardu Induk Duri Kosambi.

- Terhadap data yang diperoleh dilakukan pengolahan, perhitungan untuk mendapatkan nilai impedansi saluran dan arus hubung singkat 1 fasa ke tanah, 
untuk keperluan koordinasi rele proteksinya, tidak hanya pada titik gangguan tetapi juga pada konstribusi arus dari sumber yang mengalir ke titik gangguan. Data-data yang didapat berdasarkan peralatan-peralatan yang berada pada wilayah kerja Gardu Induk Duri Kosambi dan penyulang.

Adapun diagram alur dari rencana peneliti dapat dilihat pada bagan dibawah ini :

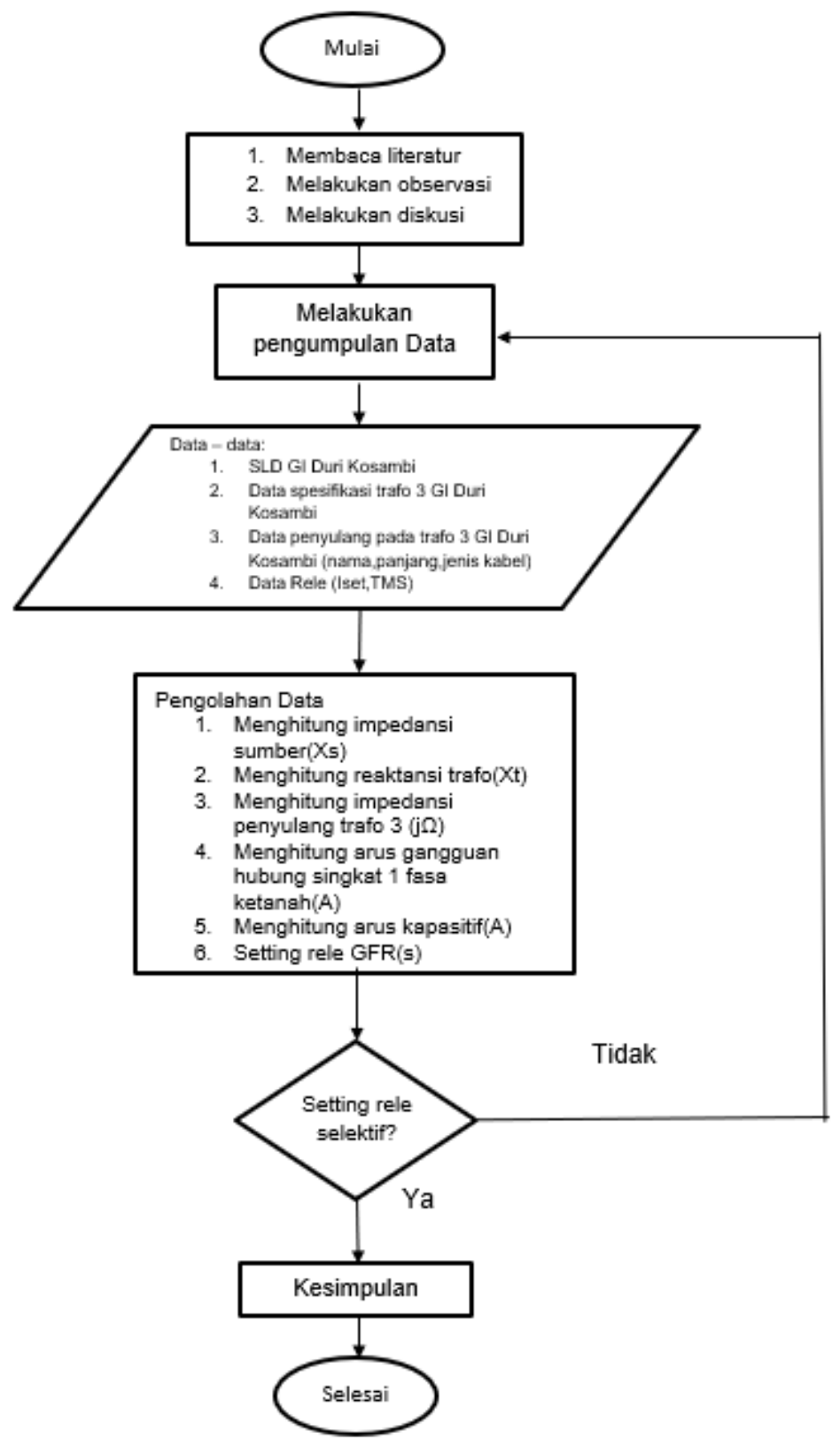

Gambar 1. Flow chart perencanaan penelitian

\subsection{Metode Analisa Data}

Metode analisa data adalah dengan menggunakan data-data pada Gardu Induk Duri Kosambi dan penyulangnya, dengan materi kajian terdiri dari :

1. Menghitung besar impedansi sumber (reaktansi), yang dalam hal ini di peroleh dari data hubung singkat di Bus $150 \mathrm{kV}$.

2. Menghitung reaktansi trafo tenaga. 
3. Menghitung impedansi pada masing - masing penyulang dan besarnya nilai impedansi eqivalen pada masing - masing penyulang.

4. Menghitung arus gangguan hubung singkat dan arus kapasitif yang dikandung masing -masing penyulang.

5. Melakukan perhitungan waktu kerja rele gangguan tanahnya (Ground Fault Relay).

\subsection{Analisis Perhitungan}

- Impedansi sumber

Arus gangguan hubung singkat disisi $20 \mathrm{kv}$ diperoleh dengan cara mengkonversikan dulu impedansi sumber di bus $150 \mathrm{kV}$ ke sisi $20 \mathrm{kV}$. Setelah dikonversi impedansinya ke sisi $20 \mathrm{kV}$ nantinya perhitungan arus gangguan hubung singkatnya menggunakan tegangan $20 \mathrm{kV}$ sebagai sumber dan tidak lagi mempergunakan tegangan $150 \mathrm{kV}$.

$$
\begin{aligned}
& X_{S C}(\text { sisi } 150 \mathrm{kV})=\frac{k V^{2}}{M V A s c} \\
& X_{S C}(\text { sisi } 20 \mathrm{kV})=\frac{k V^{2}(\text { sisi } 20 \mathrm{kV})}{k V^{2}(\text { sisi } 150 \mathrm{kV})} \times X_{S c}(\text { sisi } 150 \mathrm{kV})
\end{aligned}
$$

Untuk MVA $\mathrm{Asc}_{\mathrm{sc}}$ dapat dihitung dengan menggunakan :

$$
M V A_{s c}=\sqrt{3} \times k V \times I_{s c}
$$

- Menghitung Reaktansi Trafo

$$
X_{t}=\frac{k V^{2}(\text { sisi } 20 \mathrm{kV})}{M V A(\text { Trafo })}
$$

Tabel 1. Data Transformator

\begin{tabular}{|c|c|}
\hline Nama Trafo & Trafo 3 \\
\hline Merk & Hyundai \\
\hline No. Seri & TL-258 \\
\hline Tegangan Pengenal Primer & $150 \mathrm{kV}$ \\
\hline $\begin{array}{c}\text { Tegangan Pengenal } \\
\text { Sekunder }\end{array}$ & $20 \mathrm{kV}$ \\
\hline Daya & $60 \mathrm{MVA}$ \\
\hline Impedansi Trafo & $12,63 \%$ \\
\hline Ratio CT & $300 / 5$ \\
\hline Arus Nominal Trafo & $230 \mathrm{~A} / 1732 \mathrm{~A}$ \\
\hline Pendingin & $\mathrm{ONAN} / \mathrm{ONAF}$ \\
\hline Pembumian primer & Langsung \\
\hline Pembumian sekunder & $12 \Omega$ \\
\hline Belitan & $\mathrm{YnYnO}(\Delta 11)$ \\
\hline Frekuensi & $50 \mathrm{~Hz}$ \\
\hline
\end{tabular}

- Menghitung Impedansi urutan penyulang

$Z_{1}=Z_{2}=Z_{\text {penyulang }} \times$ Panjang penyulang

(5)

$Z_{0}=Z_{\text {penyulang }} \times$ Panjang penyulang

(6) 
Tabel 2. Data penyulang

\begin{tabular}{|c|c|c|c|c|}
\hline \multirow{2}{*}{ Nama Penyulang } & \multirow{2}{*}{ Jenis Kabel } & \multicolumn{2}{|c|}{ Impedansi Urutan } & \multirow{2}{*}{$\begin{array}{c}\text { Panjang } \\
\text { penyulang }(\mathrm{km})\end{array}$} \\
\cline { 3 - 4 } & XLPE 3X240 & $0,125+0,097 \mathrm{j}$ & $0,275+0,290 \mathrm{j}$ & 3,48 \\
\hline Dering & XLPE 3X240 & $0,125+0,097 \mathrm{j}$ & $0,275+0,290 \mathrm{j}$ & 2,25 \\
\hline Angkin & XLPE 3X240 & $0,125+0,097 \mathrm{j}$ & $0,275+0,290 \mathrm{j}$ & 6,78 \\
\hline Abad & XLPE 3X240 & $0,125+0,097 \mathrm{j}$ & $0,275+0,290 \mathrm{j}$ & 8,00 \\
\hline Niagara & XLPE 3X240 & $0,125+0,097 \mathrm{j}$ & $0,275+0,290 \mathrm{j}$ & 6,73 \\
\hline Ringkik & XLPE 3X240 & $0,125+0,097 \mathrm{j}$ & $0,275+0,290 \mathrm{j}$ & 3,65 \\
\hline Windu & XLPE 3X240 & $0,125+0,097 \mathrm{j}$ & $0,275+0,290 \mathrm{j}$ & 7,78 \\
\hline Dekade & XLPE 3X240 & $0,125+0,097 \mathrm{j}$ & $0,275+0,290 \mathrm{j}$ & 3,55 \\
\hline Kalambo & XLPE 3X240 & $0,125+0,097 \mathrm{j}$ & $0,275+0,290 \mathrm{j}$ & 3,29 \\
\hline Ringtone & XLPE 3X240 & $0,125+0,097 \mathrm{j}$ & $0,275+0,290 \mathrm{j}$ & 9,39 \\
\hline Enter & XLPE 3X240 & $0,125+0,097 \mathrm{j}$ & $0,275+0,290 \mathrm{j}$ & 4,59 \\
\hline Cad.6 & & & \\
\hline
\end{tabular}

- Menghitung arus gangguan hubung singkat

$I_{f 1 \emptyset \text { ketanah }}=\frac{3 \times E p h}{2 \times Z_{1 e q}+Z_{0 e q}}$

$I_{f 1 \emptyset \text { ketanah }}=\frac{3 \times E p h}{\sqrt{\left.3 R_{N}+2 \cdot l \cdot R_{1 j}+R_{0 j}+R_{f}\right)^{2}+\left(2 X_{s c ~ 20 k V}+2 \cdot X_{1 T}+X_{0 T}+2 . l \cdot X_{1 j}+l \cdot X_{0 j}\right)^{2}}}$

Dimana :

$I_{f} 1 \varnothing$ ketanah $=$ Nilai arus hubung singkat 3 phasa (Ampere)

$\mathrm{R}_{1 \mathrm{j}} \quad=$ Nilai resistansi dari komponen urutan positif pada jaringan $(\Omega)$

$\mathrm{R}_{0 \mathrm{j}} \quad=$ Nilai resistansi dari komponen urutan positif pada jaringan $(\Omega)$

$\mathrm{X}_{1 \mathrm{sc}} \quad=$ Nilai reaktansi dari arus hubung singkat $20 \mathrm{kV}(\Omega)$

$\mathrm{X}_{1 \mathrm{j}} \quad=$ Nilai reaktansi yang ada pada jaringan $(\Omega)$

$\mathrm{X}_{0 \mathrm{j}} \quad=$ Nilai reaktansi yang ada pada jaringan $(\Omega)$

$\mathrm{X}_{1 \mathrm{~T}} \quad=$ Nilai reaktansi trafo urutan positif $(\Omega)$

$\mathrm{X}_{\text {OT }} \quad=$ Nilai reaktansi trafo urutan nol $(\Omega)$

$\mathrm{R}_{\mathrm{f}} \quad=$ Nilai tahanan gangguan fasa fasa $(\Omega)$

$\mathrm{R}_{\mathrm{N}} \quad=$ Nilai tahanan pentanahan bernilai $12 \mathrm{ohm}(\Omega)$

$\mathrm{E}_{\mathrm{ph}} \quad=$ Tegangan fasa - netral sistem $20 \mathrm{kV}=\frac{20.000}{\sqrt{3}}(\mathrm{~V})$

$Z_{\text {leq }} \quad=$ Impedansi urutan positif (ohm)

$\mathrm{Z}_{\text {oq }} \quad=$ Impedansi urutan nol (ohm)

- Menghitung arus kapasitif penyulang

$$
I_{C E}=\frac{3 \times E_{p h}}{X_{\text {tot kapasitif penyulang }}}
$$

Untuk reaktansi total kapasitif penyulang dihitung dengan menggunakan persamaan :

$X_{\text {tot } \text { kapasitif penyulang }}=\frac{1}{2 \times 3,14 \times \text { frekuensi } \times\left(\text { kapasitansi total } \frac{\mu}{\mathrm{km}}\right)}$ 
- Setting rele gangguan tanah

Nilai setelan arus rele gangguan tanah dihitung sebesar $10 \% \mathrm{x}$ arus gangguan tanah terkecil di penyulang itu (gangguan tanah diujung penyulang), sedangkan setelan waktu tms dari rele gangguan tanah dihitung sesuai rumus dan ketentuan lokasi gangguan.

$$
\begin{aligned}
& I_{\text {set primer }}=10 \% \times I_{f 1 \text { fasa ketanah }} \\
& I_{\text {set sekunder }=I_{\text {set primer }}} \times \text { Ratio } C T
\end{aligned}
$$

- Penyetelan waktu kerja rele

Apabila telah selesai menghitung nilai setelan arus dan setelan waktu (tms) dari rele gangguan tanah pada masing-masing penyulang, perlu disetel dan diuji selektifitas kerja relenya, apakah masih menyebabkan simpatetik trip pada penyulang sehat sewaktu terjadi gangguan tanah di salah satu penyulang, dengan menggunakan persamaan inverse :

$$
t=\frac{0,14 \times T M S}{\left(\frac{I_{\text {fault }}}{I_{\text {set }}}\right)^{0,02}-1}
$$
berikut:

Untuk pengujian rele dipenyulang terganggu dengan menggunakan Ifault sebagai

$$
I_{\text {fault }}=\sqrt{\left(I_{\text {fault }}\right)^{2}+(\text { total arus kapasitif penyulang lain })^{2}}
$$

Untuk pengujian waktu pada penyulang yang tidak terganggu adalah sama dengan persamaan (14) namun bedanya $I_{\text {fault }}$ yang digunakan adalah arus kapasitif dari penyulang yang dimaksud.

\section{HASIL DAN PEMBAHASAN}

\subsection{Uraian Perhitungan}

- Perhitungan impedansi sumber

Dengan menggunakan persamaan (3), dimana diketahui short circuit level pada bus 150 kV di GI Duri Kosambi yaitu 30,03 kA maka didapat MVA hubung singkatnya dengan rumus sebagai berikut :

$M V A_{s c}=\sqrt{3} \times 150 \mathrm{kV} \times 30,03=7802,02 M V A$

$X_{S c}($ sisi $150 \mathrm{kV})=\frac{150^{2}}{7802,02}=2,88 \Omega$

$X_{s c}($ sisi $20 \mathrm{kV})=\frac{20 k V^{2}}{150 k V^{2}} \times 2,88 \Omega=0,0512 \Omega$

- Perhitungan reaktansi trafo

$X_{t}=\frac{k V^{2}(\text { sisi } 20 \mathrm{kV})}{M V A(\text { Trafo })}=\frac{20^{2} \mathrm{kV}}{60 \mathrm{MVA}}=6,67 \Omega$

Sehingga dapat dihitung untuk reaktansi urutan positif dan negatif 
$X_{t}=12,63 \% \times 6,67 \Omega=0,8424 \Omega$

Untuk reaktansi trafo urutan nolnya

$X_{t 0}=3 \times\left(X_{t 1}\right)=3 \times 0,8424 j \Omega=2,5272 j \Omega$

- Perhitungan impedansi penyulang sebagai contoh diambil penyulang 1 yaitu penyulang Dering, sebagai berikut :

1. Penyulang Dering

$0 \mathrm{~km} \quad=Z_{1}=Z_{2}=0 \mathrm{~km} \times(0,125+0,097 j) \frac{\Omega}{\mathrm{km}}=0$

$$
=Z_{0}=0 \mathrm{~km} \times(0,275+0,290 j) \frac{\Omega}{\mathrm{km}}=0
$$

$3,48 \mathrm{~km} \quad=Z_{1}=Z_{2}=3,48 \mathrm{~km} \times(0,125+0,097 j) \frac{\Omega}{\mathrm{km}}=0,435+0,3375 j \Omega$

$$
=Z_{0}=3,48 \mathrm{~km} \times(0,275+0,290 j) \frac{\Omega}{\mathrm{km}}=0,957+1,0092 j \Omega
$$

Dengan perhitungan yang sama pada semua penyulang di trafo 3 maka didapat hasil sebagai berikut :

Tabel 3. Impedansi Penyulang

\begin{tabular}{|c|c|c|c|}
\hline \multirow{2}{*}{$\begin{array}{c}\text { Nama } \\
\text { Penyulang }\end{array}$} & $\begin{array}{c}\text { Panjang } \\
\text { Penyulang } \\
(\mathrm{km})\end{array}$ & $\begin{array}{c}|c| \\
\text { Drutan Positif dan } \\
\text { Negatif }\end{array}$ & Urutan Nol \\
\cline { 3 - 4 } & 3,48 & $0,435+0,3375 j \Omega$ & $0,957+1,0092 j \Omega$ \\
\hline Dering & 2,25 & $0,2812+0,3375 j \Omega$ & $0,6188+0,6525 j \Omega$ \\
\hline Angkin & 6,78 & $0,8475+0,6577 j \Omega$ & $1,8645+1,9662 j \Omega$ \\
\hline Abad & 8,00 & $1+0,776 j \Omega$ & $2,2+2,32 j \Omega$ \\
\hline Niagara & 6,73 & $0,8412+0,6528 j \Omega$ & $1,8505+1,9517 j \Omega$ \\
\hline Ringkik & 3,65 & $0,4562+0,3540 j \Omega$ & $1,0038+1,0585 j \Omega$ \\
\hline Windu & 7,78 & $0,9725+0,7546 j \Omega$ & $2,1395+2,2562 j \Omega$ \\
\hline Dekade & 3,55 & $0,4437+0,3443 j \Omega$ & $0,0976+1,0295 j \Omega$ \\
\hline Kalambo & 3,29 & $0,4112+0,3191 j \Omega$ & $0,9048+0,9541 j \Omega$ \\
\hline Ringtone & 9,39 & $1,1737+0,9108 j \Omega$ & $2,5822+2,7251 j \Omega$ \\
\hline Enter & 4,59 & $0,5738+0,4452 j \Omega$ & $1,2622+1,3311 j \Omega$ \\
\hline Cad.6 & & &
\end{tabular}

- Perhitungan arus gangguan hubung singkat sebagai contoh diambil penyulang 1 yaitu penyulang Dering, sebagai berikut :

1. Penyulang Dering

Arus gangguan hubung singkat di $0 \mathrm{~km}$ :

If $1 \varnothing$ ketanah

$$
\begin{aligned}
& 3 \times E p h
\end{aligned}
$$

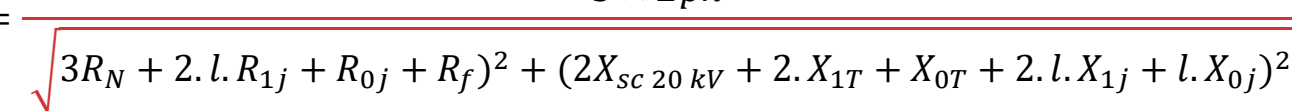

$$
\begin{aligned}
& =\frac{3 \times \frac{20.000 \mathrm{~V}}{\sqrt{3}}}{\sqrt{3 \times 12+2 \times 0 \times 0,125+0 \times 0,275)^{2}+(2 \times 0,0512+2 \times 0,8424+2,527+2 \times 0 \times 0,097+0 \times 0,290)^{2}}} \\
& =955,4 \mathrm{~A}
\end{aligned}
$$


Arus hubung singkat pada $100 \%$ panjang penyulang yaitu, 3,48 km :

$$
\begin{aligned}
& I_{f} 1 \emptyset \text { ketanah } \\
& =\frac{3 \times E p h}{\sqrt{\left.3 R_{N}+2 . l . R_{1 j}+R_{0 j}+R_{f}\right)^{2}+\left(2 X_{S c 20 k V}+2 . X_{1 T}+X_{0 T}+2 . l . X_{1 j}+\text { l. } X_{0 j}\right)^{2}}} \\
& =\frac{3 \times \frac{20.000 \mathrm{~V}}{\sqrt{3}}}{\sqrt{3 \times 12+2 \times 3,48 \times 0,125+3,48 \times 0,275)^{2}+(2 \times 0,0512+2 \times 0,8424+2,527+2 \times 3,48 \times 0,097+3,48 \times 0,290)^{2}}} \\
& =904,4 \mathrm{~A}
\end{aligned}
$$

Dengan perhitungan yang sama pada semua penyulang maka didapat hasil arus gangguan hubung singkatnya sebagai berikut :

Tabel 4. Nilai arus hubung singkat tiap penyulang

\begin{tabular}{|c|c|c|}
\hline \multirow{2}{*}{ Nama Penyulang } & \multicolumn{2}{|c|}{ Arus Hubung Singkat 1 fasa ke tanah } \\
\cline { 2 - 3 } & di 0 km & $\begin{array}{c}\text { Pada 100\% panjang } \\
\text { penyulang }\end{array}$ \\
\hline Dering & $955,4 \mathrm{~A}$ & $3,48 \mathrm{~km}=904,4 \mathrm{~A}$ \\
\hline Angkin & $955,4 \mathrm{~A}$ & $2,25 \mathrm{~km}=921,8 \mathrm{~A}$ \\
\hline Abad & $955,4 \mathrm{~A}$ & $6,78 \mathrm{~km}=859,8 \mathrm{~A}$ \\
\hline Niagara & $955,4 \mathrm{~A}$ & $8,00 \mathrm{~km}=844,5 \mathrm{~A}$ \\
\hline Ringkik & $955,4 \mathrm{~A}$ & $6,73 \mathrm{~km}=860,7 \mathrm{~A}$ \\
\hline Windu & $955,4 \mathrm{~A}$ & $3,65 \mathrm{~km}=902,1 \mathrm{~A}$ \\
\hline Dekade & $955,4 \mathrm{~A}$ & $7,78 \mathrm{~km}=846,9 \mathrm{~A}$ \\
\hline Kalambo & $955,4 \mathrm{~A}$ & $3,55 \mathrm{~km}=903,5 \mathrm{~A}$ \\
\hline Ringtone & $955,4 \mathrm{~A}$ & $3,29 \mathrm{~km}=907,1 \mathrm{~A}$ \\
\hline Enter & $955,4 \mathrm{~A}$ & $9,39 \mathrm{~km}=827,1 \mathrm{~A}$ \\
\hline Cad.6 & $955,4 \mathrm{~A}$ & $4,59 \mathrm{~km}=888,9 \mathrm{~A}$ \\
\hline
\end{tabular}

- Perhitungan arus kapasitif penyulang

Diketahui nilai kapasitansi tiap penyulang yaitu $0,273 \mu / \mathrm{km}$, maka perhitungan nilai kapasitansi total tiap-tiap penyulang didapat dengan cara mengalikan dengan $100 \%$ panjang penyulang dan didapat hasil adalah sebagai berikut :

Tabel 5. Nilai kapasitansi tiap penyulang

\begin{tabular}{|c|c|c|c|}
\hline $\begin{array}{c}\text { Nama } \\
\text { Penyulang }\end{array}$ & $\begin{array}{c}\text { Panjang } \\
\text { Penyulang } \\
(\mathrm{km})\end{array}$ & $\begin{array}{c}\text { Kapasitansi } \\
\mu / \mathrm{km}\end{array}$ & $\begin{array}{c}\text { Kapasitansi } \\
\text { total } \mu / \mathrm{km}\end{array}$ \\
\hline Dering & 3,48 & 0,273 & 0,950 \\
\hline Angkin & 2,25 & 0,273 & 0,614 \\
\hline Abad & 6,78 & 0,273 & 1,851 \\
\hline Niagara & 8,00 & 0,273 & 2,184 \\
\hline Ringkik & 6,73 & 0,273 & 1,838 \\
\hline Windu & 3,65 & 0,273 & 0,997 \\
\hline Dekade & 7,78 & 0,273 & 2,124 \\
\hline Kalambo & 3,55 & 0,273 & 0,969 \\
\hline Ringtone & 3,29 & 0,273 & 0,898 \\
\hline
\end{tabular}




\begin{tabular}{|c|c|c|c|}
\hline Enter & 9,39 & 0,273 & 2,563 \\
\hline Cad.6 & 4,59 & 0,273 & 1,253 \\
\hline
\end{tabular}

Sebagai contoh diambil penyulang 1 yaitu penyulang Dering,perhitungan arus kapasitifnya sebagai berikut :

1. Penyulang Dering

$$
X_{\text {tot kapasitif penyulang }}=\frac{1}{2 \times 3,14 \times 50 \times\left(0,950 \times 10^{-6}\right)}=3352,330 \Omega
$$

Kemudian menghitung nilai arus kapasitifnya :

$$
I_{C E}=\frac{3 \times \frac{20.000 \mathrm{~V}}{\sqrt{3}}}{3352,330 \Omega}=10,33 \mathrm{~A}
$$

Dengan perhitungan yang sama pada semua penyulang di trafo 3 maka didapat hasil arus kapasitif sebagai berikut :

Tabel 6. Nilai arus kapasitif tiap penyulang

\begin{tabular}{|c|c|c|}
\hline Nama Penyulang & $\begin{array}{c}\text { Panjang Penyulang } \\
(\mathrm{km})\end{array}$ & Arus kapasitif (A) \\
\hline Dering & 3,48 & 10,33 \\
\hline Angkin & 2,25 & 6,68 \\
\hline Abad & 6,78 & 20,13 \\
\hline Niagara & 8,00 & 23,76 \\
\hline Ringkik & 6,73 & 19,99 \\
\hline Windu & 3,65 & 10,84 \\
\hline Dekade & 7,78 & 23,10 \\
\hline Kalambo & 3,55 & 10,54 \\
\hline Ringtone & 3,29 & 9,76 \\
\hline Enter & 9,39 & 27,88 \\
\hline Cad.6 & 4,59 & 13,63 \\
\hline
\end{tabular}

- Perhitungan arus gangguan dengan memperhitungkan sumbangan arus kapasitif

Apabila pada salah satu penyulang terjadi arus gangguan hubung singkat satu fasa ke tanah, maka tiap - tiap penyulang lain yang masih dalam satu busbar akan menyumbangkan arus kapasitif ke penyulang yang terganggu melalui titik gangguan. Sebagai contoh diambil penyulang 1 yaitu penyulang Dering saat mengalami gangguan maka arus di titik gangguan adalah jumlah resultan arus hubung singkatnya dengan jumlah arus kapasitif dari tiap - tiap penyulang lainnya yang tidak terganggu. Gangguan terjadi di $0 \mathrm{~km}$ dan pada $100 \%$ panjang penyulang maka besarnya arus di titik gangguan tersebut dapat dicari dengan persamaan (14) sebagai berikut :

$$
I_{\text {fault }}=\sqrt{\left(I_{\text {fault }}\right)^{2}+(\text { total arus kapasitif penyulang lain })^{2}}
$$

1. Penyulang Dering

Arus gangguan di $0 \mathrm{~km}$ :

$$
I_{\text {fault }}=\sqrt{(955,4 A)^{2}+(166,31)^{2}}=969,78 \mathrm{~A}
$$


Vol. 10, No. 1, Juni 2020, P-ISSN 2356-1505, E-ISSN 2656-9175

https://doi.org/10.33322/sutet.v10i1.1137

Arus gangguan di $3,48 \mathrm{~km}$ :

$$
I_{\text {fault }}=\sqrt{(904,4 A)^{2}+(166,31)^{2}}=919,6 \mathrm{~A}
$$

Dengan perhitungan yang sama pada semua penyulang di trafo 3 maka didapat hasil arus di titik gangguan adalah sebagai berikut :

Tabel 7. Nilai Arus di titik gangguan tiap penyulang

\begin{tabular}{|c|c|c|c|}
\hline \multirow{2}{*}{$\begin{array}{c}\text { Nama } \\
\text { Penyulang }\end{array}$} & \multicolumn{2}{|c|}{ Panjang Penyulang } & \multirow{2}{*}{$\begin{array}{c}\text { Arus di titik } \\
\text { Gangguan (A) }\end{array}$} \\
\hline & $\%$ & $\mathrm{~km}$ & \\
\hline \multirow{2}{*}{ Dering } & 0 & 0 & 969,8 \\
\hline & 100 & 3,48 & 919,6 \\
\hline \multirow{2}{*}{ Angkin } & 0 & 0 & 970,4 \\
\hline & 100 & 2,25 & 937,3 \\
\hline \multirow{2}{*}{ Abad } & 0 & 0 & 968,1 \\
\hline & 100 & 6,78 & 873,9 \\
\hline \multirow{2}{*}{ Niagara } & 0 & 0 & 967,6 \\
\hline & 100 & 8,00 & 858,2 \\
\hline \multirow{2}{*}{ Ringkik } & 0 & 0 & 968,1 \\
\hline & 100 & 6,73 & 874,8 \\
\hline \multirow{2}{*}{ Windu } & 0 & 0 & 969,7 \\
\hline & 100 & 3,65 & 917,2 \\
\hline \multirow{2}{*}{ Dekade } & 0 & 0 & 967,7 \\
\hline & 100 & 7,78 & 860,7 \\
\hline \multirow{2}{*}{ Kalambo } & 0 & 0 & 969,7 \\
\hline & 100 & 3,55 & 918,6 \\
\hline \multirow{2}{*}{ Ringtone } & 0 & 0 & 969,9 \\
\hline & 100 & 3,29 & 922,3 \\
\hline \multirow{2}{*}{ Enter } & 0 & 0 & 966,9 \\
\hline & 100 & 9,39 & 840,3 \\
\hline \multirow{2}{*}{ Cad.6 } & 0 & 0 & 969,2 \\
\hline & 100 & 4,59 & 903,7 \\
\hline
\end{tabular}

- Penyetelan rele gangguan tanah

Untuk setelan rele yang terpasang pada penyulang dapat dihitung berdasakan arus beban maksimumnya. Syarat lain yang harus dipenuhi untuk penyetelan waktu kerja rele dengan karakteristik standar invers dengan diambil arus gangguan 1 fasa ketanah pada 
panjang maksimum penyulang. Berikut penyetelan rele gangguan tanah dengan menggunakan persamaan 11 dan persamaan 12 :

$$
\begin{aligned}
& I_{\text {set primer }}=10 \% \times I_{f 1 \text { fasa ketanah }} \\
& I_{\text {set sekunder }}=I_{\text {set primer }} \times \text { Ratio } C T
\end{aligned}
$$

Sebagai contoh diambil penyulang 1 yaitu penyulang Dering

1. Penyulang Dering

Rele gangguan tanah

Ratio $C T=400 / 5$

$$
\begin{aligned}
& I_{\text {set primer }}=10 \% \times I_{f 1 \text { fasa ketanah }} \\
& I_{\text {set primer }}=0,1 \times 904,4 \mathrm{~A}=90,44 \mathrm{~A} \\
& I_{\text {set sekunder }=} I_{\text {set primer }} \times \text { Ratio } \mathrm{CT} \\
& I_{\text {set sekunder }=} 90,44 \mathrm{~A} \times \frac{5}{400}=1,1305 \mathrm{~A}
\end{aligned}
$$

Untuk setelan TMS

Setelan TMS dapat dihitung dengan menggunakan persamaan (13) sebagai berikut :

$$
t=\frac{0,14 \times T M S}{\left(\frac{I_{\text {fault }}}{I_{\text {set }}}\right)^{0,02}-1}
$$

$\mathrm{t}=0,3 \mathrm{~s}$ untuk permulaan setting

$$
0,3=\frac{0,14 \times T M S}{\left(\frac{955,4}{90,44}\right)^{0,02}-1}=0,1034
$$

Dengan perhitungan yang sama pada semua penyulang di trafo 3 maka didapat hasil arus di titik gangguan adalah sebagai berikut :

Tabel 8. Nilai setting rele gangguan tanah tiap penyulang

\begin{tabular}{|c|c|c|c|}
\hline $\begin{array}{c}\text { Nama } \\
\text { Penyulang }\end{array}$ & Iset primer $(\mathrm{A})$ & $\mathrm{I}_{\text {set sekunder }(\mathrm{A})}$ & TMS (s) \\
\hline Dering & 90,44 & 1,1305 & 0,1034 \\
\hline Angkin & 92,18 & 1,1522 & 0,1026 \\
\hline Abad & 85,98 & 1,0748 & 0,1058 \\
\hline Niagara & 84,45 & 1,0557 & 0,1066 \\
\hline Ringkik & 86,07 & 1,0759 & 0,1057 \\
\hline Windu & 90,21 & 1,1277 & 0,1036 \\
\hline Dekade & 84,69 & 1,0587 & 0,1064 \\
\hline Kalambo & 90,35 & 1,1293 & 0,1035 \\
\hline Ringtone & 90,71 & 1,1339 & 0,1033 \\
\hline Enter & 82,71 & 1,0339 & 0,1074 \\
\hline Cad.6 & 88,89 & 1,1111 & 0,1042 \\
\hline
\end{tabular}




\section{- Uji selektifitas rele}

Pada perhitungan ini dihitung nilai selektivitas waktu kerja dari rele, pengujian selektivitas waktu kerja rele ini dilakukan setelah selesai menghitung nilai setelan arus dan setelan waktu untuk rele tanah merespon adanya gangguan (TMS) dari rele gangguan tanah pada masing - masing penyulang. Dalam pengujian selektivitas waktu kerja rele ini harus ada perbedaan waktu kerja penyulang yang terganggu dengan penyulang yang tidak terganggu sehingga tidak terjadi simpatetik trip. Berikut perhitungan selektifitas waktu kerja rele untuk tiap - tiap penyulang pada trafo 3 pada saat penyulang mengalami gangguan maupun tidak. Pada saat penyulang mengalami gangguan, arus gangguan (l fault $_{\text {f }}$ adalah arus gangguan pada penyulang tersebut ditambah dengan total arus kapasitif dari tiap tiap penyulang lainnya yang masih dalam satu busbar. Sedangkan pada saat penyulang tidak mengalami gangguan, arus gangguannya ( $\left.\mathrm{l}_{\text {fault }}\right)$ adalah arus kapasitif pada penyulang tersebut. Nilai selektifitas waktu kerja rele dapat dihitung dengan rumus sebagai berikut :

$$
t=\frac{0,14 \times T M S}{\left(\frac{I_{\text {fault }}}{I_{\text {set }}}\right)^{0,02}-1}
$$

Sebagai contoh diambil penyulang 1 yaitu penyulang Dering, dari tabel 3.6 diketahui nilai TMS untuk semua penyulang adalah $0,10 \mathrm{~s}$.

1. Selektifitas waktu kerja rele di $0 \mathrm{~km}$

- Penyulang Dering saat mengalami gangguan

$$
t=\frac{0,14 \times 0,10}{\left(\frac{969,8}{90,44}\right)^{0,02}-1}=0,288 \mathrm{~s}
$$

- Waktu kerja rele pada penyulang Dering saat gangguan di penyulang lain

$$
\begin{aligned}
t & =\frac{0,14 \times T M S}{\left(\frac{10,33}{90,44}\right)^{0,02}-1} \\
t & =-0,329 \mathrm{~s} \quad(\text { rele tidak bekerja) }
\end{aligned}
$$

2. Selektifitas waktu kerja rele pada $100 \%$ panjang penyulang

- Penyulang Dering saat mengalami gangguan

$$
t=\frac{0,14 \times 0,10}{\left(\frac{919,6}{90,44}\right)^{0,02}-1}=0,294 \mathrm{~s}
$$

- Waktu kerja rele pada penyulang Dering saat gangguan di penyulang lain

$$
\begin{aligned}
t & =\frac{0,14 \times T M S}{\left(\frac{10,33}{90,44}\right)^{0,02}-1} \\
t & =-0,329 \mathrm{~s} \text { (rele tidak bekerja) }
\end{aligned}
$$


Dengan perhitungan yang sama pada semua penyulang di trafo 3 maka didapat hasil nilai selektifitas waktu kerja rele adalah sebagai berikut :

Tabel 9. Nilai selektifitas waktu kerja rele gangguan tanah tiap penyulang

\begin{tabular}{|c|c|c|c|}
\hline \multirow[b]{2}{*}{$\begin{array}{c}\text { Nama } \\
\text { Penyulang }\end{array}$} & \multirow[b]{2}{*}{$\begin{array}{c}\text { Panjang } \\
\text { Penyulang } \\
(\mathrm{km})\end{array}$} & \multicolumn{2}{|c|}{ Waktu kerja rele (s) } \\
\hline & & $\begin{array}{c}\text { Gangguan } \\
\text { Pada } \\
\text { Penyulang }\end{array}$ & Penyulang Lain \\
\hline \multirow{2}{*}{ Dering } & $0 \%$ & 0,288 & \multirow{2}{*}{$-0,329$} \\
\hline & $100 \%$ & 0,294 & \\
\hline \multirow{2}{*}{ Angkin } & $0 \%$ & 0,290 & \multirow{2}{*}{$-0,273$} \\
\hline & $100 \%$ & 0,294 & \\
\hline \multirow{2}{*}{ Abad } & $0 \%$ & 0,282 & \multirow{2}{*}{$-0,489$} \\
\hline & $100 \%$ & 0,294 & \\
\hline \multirow{2}{*}{ Niagara } & $0 \%$ & 0,280 & \multirow{2}{*}{$-0,559$} \\
\hline & $100 \%$ & 0,295 & \\
\hline \multirow{2}{*}{ Ringkik } & $0 \%$ & 0,282 & \multirow{2}{*}{$-0,486$} \\
\hline & $100 \%$ & 0,295 & \\
\hline \multirow{2}{*}{ Windu } & $0 \%$ & 0,288 & \multirow{2}{*}{$-0,337$} \\
\hline & $100 \%$ & 0,294 & \\
\hline \multirow{2}{*}{ Dekade } & $0 \%$ & 0,280 & \multirow{2}{*}{$-0,545$} \\
\hline & $100 \%$ & 0,294 & \\
\hline \multirow{2}{*}{ Kalambo } & $0 \%$ & 0,288 & \multirow{2}{*}{$-0,332$} \\
\hline & $100 \%$ & 0,294 & \\
\hline \multirow{2}{*}{ Ringtone } & $0 \%$ & 0,288 & \multirow{2}{*}{$-0,321$} \\
\hline & $100 \%$ & 0,294 & \\
\hline \multirow{2}{*}{ Enter } & $0 \%$ & 0,278 & \multirow{2}{*}{$-0,650$} \\
\hline & $100 \%$ & 0,295 & \\
\hline \multirow{2}{*}{ Cad.6 } & $0 \%$ & 0,286 & \multirow{2}{*}{$-0,380$} \\
\hline & $100 \%$ & 0,294 & \\
\hline
\end{tabular}

\subsection{Analisis hasil perhitungan}

Dari hasil perhitungan arus kapasitif, dapat dianalisa bahwa nilai arus kapasitif tiap penyulang tidak mempengaruhi terjadinya simpatetik trip, hal ini karena $\mathrm{I}_{\mathrm{ce}}<$ iset primer , sehingga rele gangguan tanahnya tidak akan mendeteksi adanya gangguan.

Dari hasil perhitungan waktu kerja rele, dapat dianalisa bahwasanya dengan menggunakan rele inverse, simpatetik trip tidak akan terjadi. Untuk nilai dari waktu kerja rele gangguan tanah jika bernilai minus, maka bisa disimpulkan bahwa nilai dari kapasitansi yang terkandung pada penyulang tersebut tidak mempengaruhi selektifitas kerja rele gangguan tanahnya (rele tidak bekerja). Saat terjadi gangguan satu fasa ketanah pada penyulang Ringkik dimana waktu kerja rele tanahnya bernilai 0,294 detik dan untuk penyulang lain yang tidak terganggu rele di penyulang tersebut bernilai minus. Nilai minus pada waktu kerja rele tanah ini artinya bahwa rele sudah selektif atau rele tersebut tidak bekerja. Dari perhitungan yang didapat waktu kerja rele pada setiap penyulang mengindikasikan bahwa seharusnya tidak ada gangguan simpatetik trip. Namun pada tanggal 23/11/2019 pada jam 11:23, telah terjadi indikasi adanya simpatetik pada penyulang Windu dengan gangguan tidak diketahui. 
Hasil perhitungan di dapat waktu kerja rele bernilai negatif, artinya nilai tersebut seharusnya rele gangguan tanah penyulang Windu tidak bekerja. Dari hasil perhitungan selektivitas waktu kerja rele gangguan tanahnya dimana untuk waktu kerja rele dari penyulang lain yang tidak terganggu bernilai minus atau tidak bekerja, ini berarti kerja rele sudah selektif. Dengan penerapan setelan rele ini maka seharusnya simpatetik trip tidak akan terjadi lagi.

\section{KESIMPULAN DAN SARAN}

Berdasarkan penelitian yang dilakukan dapat disimpulkan bahwa nilai arus kapasitif $\left(I_{c e}\right)$ lebih kecil dari nilai arus setting relenya $\left(I_{\text {set }}\right)$, sehingga pada perhitungan waktu kerja rele gangguan tanahnya bernilai negatif. Nilai negatif ini yang menandakan bahwa nilai arus kapasitif tidak mempengaruhi kerja rele tanah. Diduga terjadinya simpatetik trip pada penyulang Windu disebabkan karena terjadi kenaikan tegangan pada fasanya dan menimbulkan gangguan baru. Atau karena adanya sebab lain, penyebab lain adanya simpatetik trip bisa disebabkan karena kesalahan pada jointing kabel. Maka peneliti memberi saran untuk pastikan keandalan dan pemeliharaan sistem proteksi berjalan dengan baik. Perlu penyetelan waktu kerja rele seselektif mungkin baik dari peralatan maupun pelaksana operasi dan koordinasinya. Bekerjanya rele tanah pada penyulang lain bisa disebabkan proses jointing pada kabel. Untuk itu perlu dibahas lebih lanjut mengenai jointing kabel.

\section{UCAPAN TERIMAKASIH}

Penulis mengucapkan terima kasih kepada PT.PLN (PERSERO) Gardu Induk Duri Kosambi yang telah memberi dukungan yang membantu pelaksanaan penelitian dan atau penulisan artikel. Semoga tulisan ini bermanfaat.

\section{DAFTAR PUSTAKA}

[1] Y. C. Silalahi, (2019), "Kajian Penyetelan Rele Proteksi Sehubungan Dengan Terjadinya Gangguan Simpatetik Trip Pada Penyulang Tegangan Menengah Di Gardu Induk Cengkareng," Jakarta. Jurusan Teknik Elektro Sekolah Tinggi Teknik PLN.

[2] A. Kamaluddin, (2019) "Analisa Proteksi Pada Penyulang Distribusi Terhadap Terjadinya Gangguan Sympathetic Trip Di Gardu Induk Jatake,"

[3] M. A. Auliq dan B. E. Prasetiyo, (2019) "Simpatetik Trip Pmt Cell 20 Kv Pada Gardu Induk Lumajang," Seminar Nasional Inovasi dan Aplikasi Teknologi di Industri 2019.

[4] M. Facta, "Simpatetik Tripping. Seminar Proteksi Teknik Elektro, UNDIP, Semarang".

[5] Y. Nuransyah, (2019), "Analisa Perhitungan Waktu Kerja Rele Tanah Dengan Indikasi Adanya Symphatetic Trip Pada Penyulang ICE 1 dan ICE 2 DI GI Lengkong,"

[6] N. E. Prasetyo, (2009), "Perhitungan Waktu Kerja Rele Karena Gangguan Simpatetik," Depok. FT UI.

[7] W. Sarimun, (2016), Proteksi Sistem Distribusi Tenaga Listrik, Depok: Garamond.

[8] Samsurizal, S., Kurniawan, D. (2019). Penyetinggan Loss Of Field Relay Proteksi Generator Pada Pembangkit Listrik Tenaga Air. Setrum: Sistem Kendali-Tenagaelektronika-telekomunikasi-komputer, 8(2), 178-185. 